\title{
A SOCIEDADE DA INFORMAÇÃO E AS TRANSFORMAÇÕES NO TURISMO
}

ANDREIA RAMOS MACHADO PONTIFÍCIA UNIVERSIDADE CATÓLICA DO RIO GRANDE DO SUL PORTO ALEGRE, RIO GRANDE DO SUL, BRASIL E-MAIL: ANDREIA.RAMOS@ACAD.PUCRS.BR

CRISTIANE MAFACIOLI CARVALHO PONTIFÍCIA UNIVERSIDADE CATÓLICA PORTO ALEGRE, RIO GRANDE DO SUL, BRASIL

E-MAIL: CRISTIANE.CARVALHO@PUCRS.BR

HTTP://DX.DOI.ORG/10.5902/2316882X21619 


\section{A SOCIEDADE DA INFORMAÇÃO E AS TRANSFORMAÇÕES NO TU- RISMO}

Resumo: Este artigo identifica o conceito de Sociedade da Informação e, por intermédio de um levantamento bibliográfico, procura-se reconhecer como estas "novas" tecnologias modificaram o segmento do turismo e quais os impactos mais significativos nos participantes deste segmento. Ao final, percebe-se que as tecnologias se constituem elementos importantes para as relações pessoais, de negócio e de lazer.

Palavras-chave: Comunicação Social; Sociedade da Informação; Turismo.

\section{LA SOCIEDAD DE LA INFORMACIÓN Y LOS CAMBIOS EN EL TURISMO}

Resumen: En este trabajo se identifica el concepto de Sociedad de la Información y, a través de una revisión de la literatura, se intenta reconocer cómo estas "nuevas" tecnologías han cambiado el sector del turismo, y cuáles son los impactos más significativo sobre los participantes de este sector. En fin, se percibe que las tecnologías son elementos importantes en las relaciones personales, en los negocios y en el placer.

Palabras-clave: Comunicación Social; Sociedad de la Información; Turismo.

THE INFORMATION SOCIETY AND THE TRANSFORMATIONS IN TOURISM

Abstrat: This article identifies the concept of Information Society and, through bibliographic research, tries to find out how these 'new' information technologies have modified tourism and what the most significant impacts on the companies which operate in this market segment are. At the end of this research, it was concluded that the information technologies consist of important elements for personal relationships, business relationships and leisure relationships.

Key-words: Social Communication; Information Technology; Tourism. 


\section{INTRODUÇÃO}

O impacto da tecnologia e seu papel na sociedade contemporânea têm sido pauta de discussões e estudos. Muitos conceitos estão sendo desvendados pelos pesquisadores na busca da compreensão de como o conhecimento e a informação, na era das "novas" tecnologias, tem desempenhado um papel de transformação na comunicação.

A atual sociedade em que o acesso à informação é democrático e global, por intermédio dos meios de comunicação, equipamentos eletrônicos e a internet, tem sido chamada de Sociedade da Informação. A partir das discussões acadêmicas, o termo Sociedade da Informação se transformou em parte do vocabulário dos cidadãos no mundo atual.

Este conceito de sociedade refere-se às transformações técnicas, organizacionais e sociais que tem como base não mais os bens de produção da sociedade industrial, mas a informação e o conhecimento propiciados pelos avanços tecnológicos.

Por consequência, os impactos desta mudança de paradigmas têm sido verificados em diversos segmentos da vida humana. Em alguns setores, como o turismo, as alterações foram significantes para a construção de um singular patamar do segmento no mundo todo e as mudanças promovidas pela globalização da informação, foram determinantes para o seu desenvolvimento.

Compreender o que é a Sociedade da Informação, seus desafios e seu impacto no turismo, proporcionará um melhor entendimento das mudanças estabelecidas no segmento nos últimos anos. Este é o objetivo deste artigo. Por meio de um levantamento bibliográfico e documental nas principais obras que tratam da Sociedade da Informação, busca-se, primeiramente, definir como se constituiu o conceito de Sociedade da Informação para, posteriormente, compreender como a sociedade tem se reestruturado perante esta concepção. Após, será identificado como esta mudança se processou no turismo e quais modificações foram observadas a partir deste momento.

$1 \quad$ O termo "novas", quando se referir a tecnologias, será utilizado entre aspas considerando que, atualmente, já não o são, mas respeitando o fato de que, na ocasião de seu lançamento (e portanto de alguns debates referidos neste texto) elas representavam uma novidade.

Rev.Cad. Comun. Santa Maria, v.21, n.1, art 5, p.111 de 123, jan/abr.2017 


\section{A CONSTRUÇÃO DE UM CONCEITO}

Os antencedentes da expressão "Sociedade da Informação", que se consagrou na década de 80 , podem ser localizados em décadas anteriores. Segundo Castells (2008), o termo "Sociedade da Informação", assim como as expressões "Tecnologias da Informação" e "Informatização" tiveram sua origem no Japão dos anos 60 , mas só foram transmitidos para o ocidente anos mais tarde.

Em 1973, Daniel Bell, um sociólogo americano, inseriu nas discussões as alterações realizadas com base nas tecnologias. Em seu livro "O Advento da Sociedade Pós-Industrial" ele não propõe a nomenclatura de "Sociedade da Informação", mas fala em uma "Sociedade Pós-industrial" cujo eixo principal será o conhecimento. Segundo ele, o período pós-moderno não representaria o aumento da eficácia das tecnologias de produção como no período moderno, mas uma ameaça ou afirmação de prioridade por parte das "novas" tecnologias que irão surgir. "A alternativa predominante determinará se a sociedade será uma serva ou a senhora dos instrumentos que serão criados" (BELL, 1973, p.67).

O conceito de pós-industrialismo, enfatizado por Bell (1973), expõe um esforço no sentido de reconhecer uma mudança na estrutura social. Segundo o autor, grande parte do desenvolvimento deste conceito foi prevista há muito tempo e se constitui como uma continuação da sociedade industrial, revendo parâmetros e determinações do período com o impacto causado pelo avanço das tecnologias. "A tecnologia representou um dos principais fatores na configuração do tempo social porque, a tecnologia mudou as relações sociais e a nossa maneira de considerar o mundo" (BELL, 1973, p. 214)

Esta inovadora estruturação dá ênfase a importância do conhecimento como alicerce de onde se organizarão o desenvolvimento econômico e a estratificação da sociedade. É possível conferir que atualmente têm-se sociedades baseadas no uso do conhecimento e que tem se tornado uma das moedas mais valorizadas pelas nações e empresas. Este conhecimento evidencia-se em dois sentidos: as fontes da inovação são decorrentes cada vez mais da pesquisa e, por conta disso, o foco da sociedade incide com maior ênfase no campo do conhecimento.

Em suma, a "Sociedade Pós-industrial" possui três componentes principais: no setor econômico, representa uma passagem da manufatura

Rev.Cad. Comun. Santa Maria, v.21, n.1, art 5, p.112 de 123, jan/abr.2017 
para os serviços; na tecnologia, é a hegemonia das modernas indústrias com bases científicas e na sociologia, é a ascensão de "novas" elites técnicas. (BELL, 1973)

Após este novo conceito de sociedade descrito por Bell (1973), onde o caráter do conhecimento se apresenta em destaque, outros autores seguiram discutindo os prováveis rumos da sociedade e, esta recebeu várias definições, de acordo com a visão de cada um deles.

O termo "Sociedade da Informação" foi transmitido para o ocidente em 1978 por Simon Nora e Alain Minc, no documento "L'informatisation de La Societè, direcionado à Presidência da República francesa". Segundo os autores a "Sociedade da Informação" escapa às análises e previsões mistificantes da sociedade pós-industrial. Ultrapassa o mundo da produção e molda as necessidades em função do seu projeto, das suas regulamentações e de seu modelo cultural. Ainda cita a sociedade como um lugar de inúmeros conflitos descentralizados e que não revelam uma análise e definição unificatória. (NORA \& MINC, 1978)

Mas foi na década de 90 que o termo "Sociedade da Informação" aparece com grande força devido ao advento da internet e das tecnologias da informação e comunicação. Para Castells (2008, p.67), as tecnologias da informação abrangem um "conjunto convergente de tecnologias , microeletrônica, computação, telecomunicações e optoeletrônica”. Ele também inclui neste conceito a engenharia genética com suas crescentes evoluções.

A partir de 1995 o termo é inserido na pauta das reuniões da Comunidade Europeia e da Organização para a Cooperação e Desenvolvimento Econômico (30 países mais desenvolvidos). O termo também foi adotado pelo governo norte-americano bem como pelo Banco Mundial.

No caso do Brasil, no início dos anos 2000, com a expansão da internet e o com uso ainda mais frequente das tecnologias, o governo por meio do esforço do Ministério da Ciência e Tecnologia, lança o "Programa Sociedade da Informação no Brasil - Livro Verde”. O programa brasileiro, de acordo com a publicação, privilegia o uso das tecnologias da informação e comunicação como essenciais para impulsionar os setores como o econômico, o social e o tecnológico.

Segundo este documento, "o advento da Sociedade da Informação é o fundamento de novas formas de organização e de produção em escala mundial, redefinindo a inserção dos países na sociedade internacional e 
no sistema econômico mundial". (TAKAHASHI, 2000, p.5)

Sendo assim, o Brasil percebeu urgência em estabelecer um programa de premissas sobre o assunto e teve como base outros programas semelhantes já existentes na Europa. Para os elaboradores, o Programa Sociedade da Informação objetivava indicar rumos para a sociedade, enfocando as iniciativas que, juntas, contribuíam para impactos positivos das tecnologias da informação e comunicação.

Porém o documento brasileiro carecia de profundidade científica e , algumas vezes, a questão era tratada apenas como tecnológica. Ele foi reformulado em 2001 e sua meta modificou para a inclusão digital, com a criação de programas que valorizam a conectividade, mas ainda deixando de lado a formação para a utilização das tecnologias, bem como a produção de conteúdo e a troca de informação.

Neste ano foi criado o CGEE - Centro de Gestão e Estudos Estratégicos, organização social supervisionada pelo Ministério da Ciência e Tecnologia. A tarefa inicial do Centro foi a elaboração do Livro Branco da Ciência e Tecnologia, contendo orientações estratégicas de longo prazo, abrangendo as "novas" tecnologias.

Em maio de 2010 o governo lança o Livro Azul onde constam elementos importantes de orientação para lidar com os desafios da política de ciência, tecnologia e inovação para que ela se torne uma política de Estado. Neste documento um dos temas principais é o fato de ter a Ciência, Tecnologia e Inovação como partes integrantes do desenvolvimento sustentável, com atividades de pesquisa, desenvolvimento e inovação nas empresas e incorporação de avanços nas políticas públicas. Além das tecnologias da informação, este documento contempla as tecnologias para a agricultura, bioenergia, saúde, pré-sal e, também, sobre as tecnologias que eles chamam de "portadoras do futuro", sendo elas: nanotecnologia, biotecnologia e formas de energia. Atualmente está em vigor o PPA 20122015 (Plano Mais Brasil) relacionados com o Ministério da Ciência, Tecnologia e Inovação (MCTI, 2015).

\section{A REVOLUÇÃO TECNOLÓGICA E OS NOVOS PARAdIGMAS}

Mas o que seria esta revolução tecnológica que possibilitou esta mudança social no mundo pós-moderno? Para Bell (1973) o progresso tecnológico consiste no que há de melhor em métodos e organização para 
aumentar a eficiência do capital antigo, assim como do novo. Para Castells (2008), é uma transformação da "cultura material" devido a um novo paradigma tecnológico que tem sua organização baseada nas tecnologias da informação. É com este conceito que se procurará compreender de que maneira esta revolução impactou na sociedade humana.

Há alguns anos, a maior parte dos discursos sobre a revolução da tecnologia tratava de fazer previsões e suposições sobre a manipulação ideológica e o domínio dos meios de comunicação. Não se pode deixar que estas características mascarem a importância deste fato para a história da comunicação mundial. Segundo Castells (2008), a revolução da tecnologia é um evento histórico da mesma importância que teve a Revolução Industrial no século XVIII, pois também proporcionou uma modificação nos padrões econômicos, sociais e culturais.

Outro aspecto importante da revolução tecnológica da Sociedade da Informação é que as antecessoras ocorreram apenas em algumas localidades e demoraram a se expandir. As "novas" tecnologias difundiram-se de forma rápida e veloz, pelo globo, conectando o mundo por meio da informação. Ainda existem localidades que estão desconectadas deste novo sistema, demonstrando, conforme Castells (2008, p. 70) que "a velocidade da difusão tecnológica é seletiva tanto social quanto funcionalmente". E, apesar dos antecessores das tecnologias da informação com base na microeletrônica já serem observados antes dos anos 40, somente na década de 70 é que se difundiram amplamente, convergindo para uma mudança de paradigmas sociais.

E foi nesta época que os EUA e o mundo capitalista sofreram com a crise econômica, que motivou uma reestruturação do sistema em escala global. E, por mais que exista uma coincidência histórica entre a crise e as "novas" tecnologias, é incerto reconhecer que estas são uma reação do capitalismo. O que se percebe, nos principais estudos sobre o tema, é que, de fato, o surgimento das diferentes tecnologias neste período, relaciona-se a uma dinâmica independente da descoberta tecnológica. Sendo assim, as tecnologias anteriormente descobertas seguiram seu processo de aperfeiçoamento e possibilitaram a criação de outras.

Conforme Castells (2008), na década de 80, as tecnologias da informação exerceram papel fundamental na reestruturação organizacional e econômica que o capitalismo sofreu, principalmente nos países do G-7. Assim, não se pode afirmar que as "novas" tecnologias foram uma reação

Rev.Cad. Comun. Santa Maria, v.21, n.1, art 5, p.115 de 123, jan/abr.2017 
do capitalismo, mas que foram base na reestruturação econômica do período. Então, desta forma, pode-se dizer que a revolução da tecnologia da informação dependeu de um contexto cultural, histórico e econômico que deram o rumo da sua evolução.

$\mathrm{E}$, neste contexto, a característica de metrópole da maioria dos lugares onde a revolução da informação teve seu início, pode indicar que o componente primordial em seu desenvolvimento foi a capacidade de sinergia com base em conhecimentos e informações, relacionados à produção da indústria e a aplicação comercial.

Diferentemente de qualquer outra revolução que se pode referir, o centro da transformação que se vive na revolução tecnológica refere-se às tecnologias da informação. E o que a caracteriza não é a centralização no conhecimento e na informação, apesar de toda sua importância já ter sido evidenciada por diversos autores, mas o que realmente é o cerne da questão em voga, é a aplicação desses conhecimentos e dessa informação para a geração de conhecimentos e de dispositivos de comunicação da informação, em um ciclo de retroalimentação cumulativo entre inovação e uso (CASTELLS, 2008). Neste processo, as tecnologias congregaram-se para formar um paradigma sociotecnológico.

Uma das primeiras características deste novo paradigma é a de que a informação é sua matéria-prima: "são tecnologias para agir sobre a informação, não apenas informação para agir sobre a tecnologia, como foi o caso das revoluções anteriores" (CASTELLS, 2008, p. 108). O segundo ponto importante atribui-se à penetrabilidade dos efeitos das "novas" tecnologias, que orienta, sem ser determinante, todos os processos da atividade humana e coletiva, devido à informação ser integrante de toda esta prática. $O$ terceiro aspecto é a lógica de redes que se formam usando essas tecnologias, preservando a flexibilidade.

Este, aliás, é outro item importante no paradigma das "novas" tecnologias. Os processos, as organizações e instituições podem ser alteradas pela reorganização de seus componentes, dando uma capacidade de reconfiguração importante a este paradigma, já que a sociedade está em constante mudança. Porém, Castells (2008) chama a atenção de que esta flexibilidade pode ser utilizada como tendência repressora, se quem redefine as regras sempre forem os mesmos poderes constituídos. Então é necessário manter uma distância entre o surgimento de novos processos sociais facilitados pelas tecnologias e a extrapolação das consequências

Rev.Cad. Comun. Santa Maria, v.21, n.1, art 5, p.116 de 123, jan/abr.2017 
para a sociedade.

Além disso, esta flexibilidade incorpora a ideia de aprendizagem em vários níveis. Um dos principais é a constante adaptação de trabalhadores e consumidores com as novidades tecnológicas, sendo o aperfeiçoamento técnico e científico um requisito importante na Sociedade da Informação.

Ainda, cabe salientar uma quinta característica inerente a este processo: a crescente convergência de tecnologias específicas para um sistema integrado, em que as tecnologias antigas ficam impossibilitadas de se distinguir em separado, promovendo a integração das tecnologias em sistemas de informação. Esta convergência reforça a sinergia resultante da penetrabilidade das tecnologias da informação.

Sendo assim, o paradigma da tecnologia da informação evolui para sua abertura como uma rede de acessos múltiplos. "Abrangência, complexidade e disposição em forma de rede são seus principais atributos" (CASTELLS, 2008, p. 113).

\section{A INTERNET E A COMUNICAÇÃO EM REDE}

A internet é, sem dúvida, um dos avanços mais transformadores que o mundo da comunicação viveu até então. Ela nasceu de um projeto de pesquisa militar (ARPA: Advanced Research Projects Agency), no período da guerra fria, no final dos anos 50 e início dos anos 60. Mas foi no final dos anos 80 , com o surgimento dos primeiros provedores de acesso, que a internet se tornou mais acessível.

Alguns anos mais tarde, quando a tecnologia digital permitiu a utilização de todos os tipos de mensagens que incluíam som, imagens e dados, criou-se uma rede que geraram as condições tecnológicas para a comunicação global. A primeira rede de computadores entrou em funcionamento em 1969, aberta aos centros de pesquisa que colaboravam com o governo americano, mas os cientistas começaram a usá-la para suas próprias comunicações tornando-se difícil separar as pesquisas com fins militares das comunicações científicas da época, tendo sua divisão estabelecida somente em 1983 (CASTELLS, 2008).

No final da década de 90, o poder de comunicação da internet, concomitantemente com os avanços tecnológicos, provocou mais uma mudança importante na Sociedade da Informação. A comunicação na internet é distribuída numa rede em torno de servidores da web que usam os mes-

Rev.Cad. Comun. Santa Maria, v.21, n.1, art 5, p.117 de 123, jan/abr.2017 
mos protocolos e com capacidade de acesso a megasservidores. Assim, o processamento, aplicativos e dados ficam armazenados nos servidores da rede, possibilitando que os diversos dispositivos existentes comuniquem-se entre si.

Conforme Castells (2008), "a lógica do funcionamento de redes, cujo símbolo é a Internet, tornou-se aplicável a todos os tipos de atividades, a todos os contextos e a todos os locais que pudessem ser conectados eletronicamente". Apesar de ainda existirem muitos indivíduos que não possuem acesso à internet, atualmente são milhões de usuários de redes no mundo inteiro, abrangendo todos os aspectos da comunicação. $O$ surgimento da sociedade em rede, não pode ser entendido sem a interação de duas tendências: o desenvolvimento das "novas" tecnologias e o desejo da antiga sociedade de reaparelhar-se com o uso do poder que elas proporcionariam.

O autor cita que o processo de formação e difusão da internet e das redes de interatividade, delineou a estrutura do meio de comunicação na rede, nos hábitos dos usuários e nos padrões de comunicação. $O$ acesso a esta rede é aberto, sob a lógica da tecnologia, possibilitando amplo acesso público, mas ainda pode-se verificar uma desigualdade social no domínio eletrônico, reflexo de políticas públicas ineficazes e burocracias do sistema capitalista. Mas, mesmo assim, é possível propor que se esteja vivenciando uma sociedade interativa.

Nesta sociedade vivenciada pela interação via internet, que amplia seu espectro de comunicação com o passar do tempo, a facilidade do acesso à informação impactou e evidenciou as características dos usuários destas plataformas. A partir disso, diversos aspectos sociais e organizacionais estão sofrendo alterações constantes, dando uma nova dinâmica à Sociedade da Informação.

\section{O IMPACTO NO TURISMO}

A revolução das tecnologias da comunicação na Sociedade da Informação foi significativa para o segmento do turismo. Devido ao fato do "produto" turístico ser intangível, não podendo ser examinado antes da compra, a informação é peça fundamental no setor.

O rápido crescimento do volume de viagens nos anos 90 facilitou a entrada das "novas" tecnologias no turismo e elas foram utilizadas para

Rev.Cad. Comun. Santa Maria, v.21, n.1, art 5, p.118 de 123, jan/abr.2017 
"melhorar a gestão, desenvolvimento de novos produtos, aperfeiçoamento da comunicação, ampliação das experiências de viagens e personalização do atendimento" (GUIMARÃES e BORGES, 2008, p. 10).

Diversos fatores fizeram das tecnologias da comunicação uma parte importante do turismo. Um destes fatores foi a necessidade econômica, visto que a globalização amplia a concorrência e exige eficiência e agilidade. Os turistas que passaram a receber informações de diferentes formas aumentaram suas expectativas e esperam resolver de forma rápida, eficaz e segura suas viagens.

Mas as "novas" tecnologias, especialmente a internet, inicialmente representaram uma ameaça para os agentes de turismo, principalmente pelo fácil acesso às informações antes disponibilizadas somente pelos intermediários e também pelos diferentes produtos oferecidos para compra online. De fato, o negócio tradicional das agências de viagens foi impactado pela chegada da internet, pois muitos usuários passaram a ter relação direta com os aparelhos turísticos, como as companhias aéreas, hotéis, parques, entre outros. Por conseguinte, só continuaram no negócio as agências que buscaram utilizar a tecnologia a seu favor.

Desta maneira, os agentes passaram a atuar como "consultores" de viagens, ao contrário de apenas intermediários no processo de compra e venda. Passaram a agir como um "filtro" das informações contidas na internet, nem sempre confiáveis, orientando os turistas sobre o que é ou não seguro (GUIMARÃES e BORGES, 2008). Fazendo isso, as agências dão ênfase para determinados fornecedores turísticos na rede, recebendo gratificações dos mesmos pelo uso. Desta forma, a rede de parceiros das agências que antes era restrita a algumas operadoras de turismo soberanas, amplia consideravelmente e novos produtos podem ser oferecidos.

A agilidade com que os processos são executados na internet proporciona que o turista resolva, rapidamente, todas as etapas da viagem em uma única visita na agência, recebendo todas as informações necessárias para a realização da viagem, da passagem aérea ao seguro de viagem.

Contudo, com a ampliação do acesso a internet, as informações turísticas ficaram mais acessíveis, promovendo uma reconfiguração importante no processo comercial e muitos turistas passaram a executar o processo de compra diretamente com os fornecedores. Esta revolução teve início com os portais das companhias aéreas que passaram a oferecer seus produtos diretamente aos passageiros, dispensando o uso dos programas an-

Rev.Cad. Comun. Santa Maria, v.21, n.1, art 5, p.119 de 123, jan/abr.2017 
teriores (GDS-Global Distribuition System), somente utilizados pelos agentes de viagens.

Segundo Guimarães e Borges (2008), a internet permite operações em tempo real e oferece a este comprador que quer ser o sujeito da sua viagem, subsídios para a escolha de seus roteiros turísticos de férias ou negócios, representando economia de tempo e de recursos financeiros. Além disso, o fato da internet estar disponível durante as 24 horas do dia, proporciona ao turista a liberdade de acesso a qualquer hora, de acordo com sua conveniência e no ritmo que desejar. A disponibilidade de tradução online das informações permite aos fornecedores ampliarem seus consumidores, superando as barreiras linguísticas.

Desta forma, além de o turista ter as informações necessárias para o seu processo de decisão de compra, os fornecedores também se utilizam das tecnologias de informação e comunicação ao seu favor. O setor de eventos, por exemplo, ganhou a possibilidade de divulgação de forma global, podendo receber inscrições e pagamentos de qualquer parte do mundo. Além disso, as facilidades de transmissão pela internet fazem com que se amplie o alcance dos eventos, podendo ser compartilhado por pessoas em diversos países. "A utilização das tecnologias de gravação e transmissão dos eventos trouxe a possibilidade de criação de versões diferentes do mesmo evento, que podem ser distribuídas a usuários com expectativas e necessidades diferenciadas" (GUIMARÃES e BORGES, 2008, p. 11).

Também os meios de hospedagens tem a internet como sua aliada. O setor de hotelaria pode divulgar amplamente seus serviços, disponibilizando seu sistema de reservas diretamente ao turista. Além do mais, podem utilizar a internet como benefício aos hóspedes, disponibilizando o acesso nos quartos, assim como, na realização de encontros de negócios, com a possibilidade de vídeo conferência, entre outros benefícios. Os sistemas de informação também são utilizados pelo setor hoteleiro como forma de redução de custos operacionais e maximização da capacidade de ocupação, assim como fazendo previsões e gestão de acomodações e tarifações, auxiliando o gestor, desta forma, no monitoramento do meio de hospedagem.

Outro fornecedor que também se beneficia destes sistemas de informações, são os restaurantes. Utilizam-se das tecnologias para agilizar os pedidos, além de facilitar o pagamento. Os turistas podem obter as informações necessárias sobre os restaurantes disponíveis, seus cardápios,

Rev.Cad. Comun. Santa Maria, v.21, n.1, art 5, p.120 de 123, jan/abr.2017 
valores, localização e realizar a reserva, se necessário, no site de cada estabelecimento.

Por meio da internet os turistas também podem decidir sobre as atrações que desejam visitar. Além de visualizar as oportunidades de lazer que cada atração disponibiliza, pode fazer reservas e comprar ingressos por meio da internet. Dentro das atrações, terminais de autoatendimento, trazem informações adicionais aos turistas.

Desta forma é possível perceber que as "novas" tecnologias provocaram mudanças de paradigmas no turismo, mas especialmente de forma benéfica, tanto para os turistas quanto para os fornecedores, possibilitando uma maior integração do setor. Atualmente o segmento do turismo não se sustenta mais sem a utilização da tecnologia e isto reforça o conceito de que sem o trabalho em rede e a interatividade propostas pela internet, não será possível continuar no setor com sucesso.

\section{CONSIDERAÇÕES FINAIS}

Enfim, é fato que a sociedade vem se modificando e acompanhando a evolução histórica de um paradigma da informação proposto pelas "novas" tecnologias. Os desafios da Sociedade da Informação são muitos e englobam diversos setores.

A revolução tecnológica não é mais um evento sócio histórico, mas uma constante na sociedade atual. Elas não são mais simplesmente produtos tecnológicos, mas são novas experiências de comunicação e interação e estão presentes no dia a dia de cada indivíduo.

No segmento do turismo as tecnologias da informação e comunicação representam um ponto de significativas mudanças de paradigmas. Pode-se dizer que a Sociedade da Informação alçou o turismo a patamares globais e transformou as melhores práticas, redefinindo o perfil do turista, que se tornou mais independente e exigente.

As tecnologias provocam efeitos no consumidor e nos demais participantes do processo do turismo, por meio do acesso a informação, seja de uso pessoal ou profissional, exigindo uma reestruturação nos processos turísticos. "A transição do velho mundo dos negócios para o mundo digital oferece as organizações oportunidade de crescimento, ao mesmo tempo configura um cenário repleto de desafios, gerados por estas mudanças" (GUIMARÃES e BORGES, 2008, p.43). A revolução tecnológica promoveu

Rev.Cad. Comun. Santa Maria, v.21, n.1, art 5, p.121 de 123, jan/abr.2017 
grandes transformações no mundo. No turismo isso se tornou ainda mais evidente, ao ponto de se tornar prerrogativa para a sobrevivência do setor, especialmente para os fornecedores de serviços turísticos.

Esta capacidade de receber informações também fomenta um mercado recém-explorado pelo turismo: o turismo "desplugado". Ao mesmo tempo em que se vive conectado todas as horas do dia, começa-se a perceber que existe uma dependência digital e muitos estão procurando formas de se "desconectar". Vislumbrando uma oportunidade, agentes de viagens especializados buscam oferecer experiências off-line aos turistas. Nestes locais o acesso à internet não está disponibilizado, proporcionando aos turistas descansar não somente o corpo, mas também a mente.

Desta forma nota-se que, na Sociedade da Informação, o turismo tornou-se um novo segmento, mais interativo, mais atraente, mais dinâmico, onde as tecnologias são fundamentais e representam oportunidades para quem delas souber tirar o melhor proveito.

Portanto, identifica-se que a tecnologia alterou a forma de agir do turista, promovendo uma verdadeira revolução nos processos turísticos. A intensidade e a velocidade com que surgiram, alteraram as possibilidades de comunicação no segmento e infringiram alterações nas organizações, tornando o turismo mais competitivo e representativo dentro da economia mundial.

\section{REFERÊNCIAS}

BELL, Daniel. O Advento da Sociedade Pós-Industrial. São Paulo: Cultrix, 1973.

CASTELLS, Manuel. A Sociedade em Rede. São Paulo: Paz e Terra, 2008.

GUIMARÃES, André Sathler, BORGES, Marta Poggi e. e-turismo: internet e negócios do turismo. São Paulo: Cengage Learning, 2008.

MCTI. MCTI. 08 de outubro de 2015. http://www.mcti.gov.br/.

NORA, Simon \& MINC, Alain. L'informatisation de la Societè. Paris: La Documentatio Française, 1978.

TAKAHASHI, Tadao. Livro Verde. Brasília: Ministério da Ciência e Tecnologia, 2000. 


\section{Andreia Ramos Machado}

Mestranda em Comunicação Social pela PUCRS. MBA em Marketing pela Fundação Getúlio Vargas. Graduação em Publicidade e Propaganda pela Unisinos/RS e em Gestão do Turismo pela Universidade Católica de Brasília/DF. Consultora de Comunicação e Marketing. E-mail: andreia.ramos@acad.pucrs.br

\section{Cristiane Mafacioli Carvalho}

Doutorado em Ciências da Comunicação pela Unisinos (2004), Mestrado em Comunicação pela UFRJ (1999), Graduada em Comunicação Social - Publicidade e Propaganda pela PUCRS (1994). Professora adjunta da PUCRS.

E-mail: cristiane.carvalho@pucrs.br

RECEBIDO EM: 29/03/2016

ACEITO PARA PUBLICAÇÃO: 29/05/2016 